\title{
CONTROLE DA BIOSSÍNTESE DE POLI-HIDROXIALCANOATOS BACTERIANOS ATRAVÉS DO FLUXO DE SUBSTRATOS
}

Rafael Costa Santos Rocha*, Fabrício Saab Pereira, Marilda Keico Taciro, Maria Filomena de Andrade Rodrigues e José Geraldo da Cruz Pradella

Divisão de Química Agrupamento de Biotecnologia, Instituto de Pesquisas Tecnológicas do Estado de São Paulo S.A., Av. Prof. Almeida Prado, 532, 5508-901 São Paulo - SP, Brasil

Recebido em 24/10/05; aceito em 20/4/06; publicado na web em 30/8/06

CONTROL OF THE BIOSYNTHESIS OF BACTERIAL POLYHYDROXYALKANOATES THROUGH THE FLUX OF SUBSTRATES. Manipulation of the flux of substrates was utilized to control the amount of 3-hydroxyvalerate and 3-hydroxy-4pentenoate produced by Burkohlderia sp. The $3 \mathrm{HV}$ production rate was directly proportional to the propionic acid uptake rate with the last one completely directed to $3 \mathrm{HV}$ biosynthesis. The $3 \mathrm{HPE}$ production rate was inversely proportional to the sucrose uptake rate probably due to operation of the glyoxylate cycle.

Keywords: polyhydroxyalkanoates; P3HB-co-3HV; P3HB- $b$-3HPE.

\section{INTRODUÇÃO}

Poli-hidroxialcanoatos (PHA) são poliésteres de ácidos hidroxialcanóicos, acumulados por diversas bactérias na forma de grânulos intracelulares, que atingem até $80 \%$ em peso seco da biomassa bacteriana ${ }^{1-3}$. Os PHA são biodegradáveis e biocompatíveis, sendo sintetizados a partir de matérias-primas renováveis, como açúcar de cana $^{4-6}$. Suas aplicações vão desde embalagens e materiais descartáveis, matriz para liberação controlada de fármacos até implantes e moldes na área médica ${ }^{7-11}$.

A estrutura geral dos PHA está representada na Figura 1, onde n é 1, 2, 3 ou 4 para 3-hidroxialcanoatos, 4-hidroxialcanoatos, 5hidroxialcanoatos ou 6-hidroxialcanoatos, respectivamente ${ }^{12}$. O radical $\mathrm{R}$ pode possuir uma cadeia de até 13 carbonos, ramificada ou não; pode conter grupos aromáticos, cadeias cíclicas, átomos de cloro, flúor ou nitrogênio ${ }^{13}$.

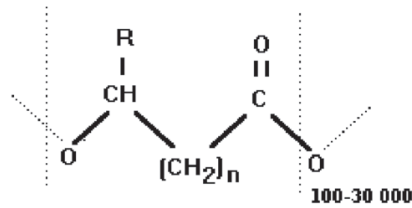

Figura 1. Estrutura geral do poli-hidroxialcanoatos

Para o acúmulo destes biopolímeros, a maioria dos microrganismos devem estar submetidos a condições de cultivo limitadas em um nutriente essencial ao crescimento ( $\mathrm{N}, \mathrm{P}, \mathrm{Mg}$ e oxigênio) $)^{1,2} \mathrm{e}$ com fonte de carbono em excesso como carboidratos ou ácidos carboxílicos. Para a biossíntese de poli-3-hidroxibutirato-co-3hidroxivalerato (P3HB-co-3HV) é necessário que se forneça, além de um carboidrato para gerar moléculas de acetil-CoA, responsável pela formação do monômero 3-hidroxibutirato $(3 \mathrm{HB})^{14}$, um substrato precursor, geralmente o ácido propiônico ou ácido valérico, ambos com estrutura similar ao monômero 3-hidroxivalerato (3HV). Por outro lado, a biossíntese da blenda poli-3-hidroxi- $b$-4-pentenoato (P3HB-b-3HPE), produzida por algumas linhagens do gênero

*e-mail: rocharcs@usp.br
Burkholderia sp. isoladas de solo, necessita apenas de uma única fonte de carbono e energia ${ }^{15}$.

A manipulação dos fluxos de substratos utilizados para síntese destes biopolímeros pode levar à produção de polímeros e copolímeros com diferentes composições e propriedades físico-químicas adequadas para as diversas aplicações ${ }^{10}$. No presente trabalho, foi estudada a relação dos fluxos de substratos com as velocidades de biossíntese dos monômeros componentes de dois poli-hidroxialcanoatos: $\mathrm{P} 3 \mathrm{HB}-$ co-3HV, produzido por Burkholderia sacchari IPT 189 e P3HB-b3HPE, produzido por Burkholderia cepacia IPT 064.

\section{PARTE EXPERIMENTAL}

\section{Microrganismos}

Foram utilizadas as linhagens de Burkholderia sacchari IPT 189, mutante prp de Burkholderia sacchari IPT 101 (LMG 19450) $^{16}$ e Burkholderia cepacia IPT 064 (DSMZ 9242) 4 criopreservadas a $80^{\circ} \mathrm{C}$ no banco de cepas do Agrupamento de Biotecnologia do IPT.

\section{Condições de cultivo}

Para o preparo do pré-inóculo, foi retirado $1 \mathrm{~mL}$ da(s) cultura(s) estoque(s) mantida(s) em freezer $-80{ }^{\circ} \mathrm{C}$, e inoculado em $300 \mathrm{~mL}$ de meio caldo nutriente $(\mathrm{CN})$ contendo $3 \mathrm{~g} / \mathrm{L}$ de extrato de carne e $5 \mathrm{~g} /$ $\mathrm{L}$ de peptona bacteriológica, incubadas em agitador rotativo a 200 rpm e $30{ }^{\circ} \mathrm{C}$ por $18 \mathrm{~h}$. Cerca de $10 \%$ (v/v) do pré-inóculo foi transferido para meio mineral ${ }^{17}$ (MM1): sacarose $10 \mathrm{~g} / \mathrm{L} ; \mathrm{KH}_{2} \mathrm{PO}_{4} 1,5 \mathrm{~g} /$ $\mathrm{L} ; \mathrm{Na}_{2} \mathrm{HPO}_{4} 3,54 \mathrm{~g} / \mathrm{L} ;\left(\mathrm{NH}_{4}\right)_{2} \mathrm{SO}_{4} 3 \mathrm{~g} / \mathrm{L} ; \mathrm{MgSO}_{4} 0,2 \mathrm{~g} / \mathrm{L} ; \mathrm{CaCl}_{2} 0,01$ $\mathrm{g} / \mathrm{L}$; citrato férrico amoniacal $0,06 \mathrm{~g} / \mathrm{L}$ e solução de elementos tra$\operatorname{ços}^{18} 1 \mathrm{~mL} / \mathrm{L}$ e incubado em agitador rotativo a $200 \mathrm{rpm}$ e $30{ }^{\circ} \mathrm{C}$ por $20 \mathrm{~h}$. $1 \mathrm{~L}$ da cultura resultante foi inoculada em biorreator de bancada (Biostat Braun modelo ED, Alemanha) aerado e agitado mecanicamente, contendo $6 \mathrm{~L}$ de meio de cultura. Os biorreatores equipados com 4 chicanas e 3 turbinas do tipo Rushton, controles automáticos de temperatura mantida a $32{ }^{\circ} \mathrm{C}$ para B. sacchari e $30{ }^{\circ} \mathrm{C}$ para B. cepacia, e oxigênio dissolvido (acima de $20 \%$ da saturação) foram munidos de bombas e balanças para introdução de soluções dos substratos e soluções para controle de $\mathrm{pH}$. 
O meio mineral utilizado para cultivo em biorreatores (MM2) apresentou a seguinte formulação $(\mathrm{g} / \mathrm{L})$ : sacarose $30 ; \mathrm{KH}_{2} \mathrm{PO}_{4} 1,5$; $\left(\mathrm{NH}_{4}\right)_{2} \mathrm{SO}_{4} 1,83 ; \mathrm{MgSO}_{4} 0,55 ; \mathrm{CaCl}_{2} 0,02$; citrato férrico amoniacal 0,05 e solução de elementos $\operatorname{traços}^{18} 2 \mathrm{~mL} / \mathrm{L}$. Os cultivos foram conduzidos em duas fases: a fase de crescimento (regime descontínuo) sem limitação de nutrientes essenciais ao crescimento e a fase de acúmulo (regime descontínuo alimentado), na qual foi efetivada a limitação da fonte de nitrogênio para acúmulo intracelular dos biopolímeros P3HB-co-3HV e P3HB- $b$-3HPE. O pH foi mantido em 7,0 com auxílio de soluções de $\mathrm{NH}_{4} \mathrm{OH}(28 \%)$ e $\mathrm{H}_{2} \mathrm{SO}_{4} 4 \mathrm{~N}$ durante a fase de crescimento e $\mathrm{NaOH} 4 \mathrm{~N} \mathrm{e}_{2} \mathrm{SO}_{4} 4 \mathrm{~N}$ durante a fase de acúmulo. Após o esgotamento da fonte de carbono e nitrogênio foi alimentado ao biorreator uma solução contendo sacarose e ácido propiônico para o acúmulo de P3HB-co-3HV e uma solução contendo apenas sacarose para o acúmulo de P3HB- $b$-3HPE. As soluções alimentadas continham $250 \mathrm{~g} / \mathrm{L}$ de fontes de carbono.

Para os ensaios de produção do copolímero, a vazão específica de alimentação $\left(\phi_{c}\right)$ foi constante $(0,15 \mathrm{~g}$ de substrato/g de biomassa residual .h) e a relação entre os substratos sacarose e ácido propiônico (sac/prop) variou entre 10:1; 19:1; 30:1 e 61,5:1. Para formação da blenda de P3HB- $b$-3HPE, variou-se a vazão específica de alimentação $(0,05 ; 0,075 ; 0,15$ e $0,30 \mathrm{~g}$ de sacarose/g de biomassa residual.h).

\section{Metodologias analíticas}

Durante os ensaios, periodicamente foram retiradas alíquotas para a execução das seguintes análises: concentração de carboidratos (sacarose, glicose e frutose), ácidos carboxílicos (ácidos acético e propiônico), concentração de biomassa total e residual, nitrogênio amoniacal, teor e composição dos biopolímeros.

Os carboidratos foram determinados por cromatografia líquida e os ácidos carboxílicos, por cromatografia gasosa ${ }^{19}$. A concentração de biomassa total $(\mathrm{Xt})$ foi determinada por gravimetria filtrando-se as amostras em membranas de poro $0,45 \mu \mathrm{m}$. As membranas e as células foram secas a $105^{\circ} \mathrm{C}$ até massa constante ${ }^{20}$. O teor e a composição dos biopolímeros foram determinados por cromatografia gasosa, após realização de propanólise ${ }^{21}$. A biomassa residual (Xr) foi calculada como $\mathrm{Xr}=\mathrm{Xt}$-PHA. O PHA é a soma dos monômeros constituintes de cada um dos biopolímeros estudados.

A vazão específica de alimentação $\left(\phi_{c}\right)$ para cada ensaio foi calculada $^{22}$ pelas Equações 1 e 2:

$\phi_{\mathrm{c}}=\frac{F \times\left(\text { sacarose }_{a l}+\text { propionico }_{a l}\right)}{X r \times V}$

$\phi_{c}=\frac{F \times\left(\text { sacarose }_{a l .}\right)}{X r \times V}$

onde sacarose $_{\text {al. }}$ e propiônico ${ }_{\text {al. }}$ são as concentrações de sacarose e ácido propiônico, respectivamente, introduzidas ao biorreator durante a fase de acúmulo; $\mathrm{F}$ é a vazão volumétrica das soluções de alimentação; Xr, a concentração de biomassa residual e V, o volume do biorreator.

As velocidades específicas de formação de $3 \mathrm{HB}$, $3 \mathrm{HV}$ e $3 \mathrm{HPE}$ e do consumo dos substratos sacarose e ácido propiônico foram avaliadas segunda a relação $1 / \mathrm{Xr}(\mathrm{d} N / \mathrm{dt})$ onde $N$ representa a concentração destas variáveis, sendo expressas em mmoles da substân$\mathrm{cia} / \mathrm{g}$ de biomassa residual por h. Estas velocidades foram então normalizadas, fazendo-se sua divisão pela velocidade máxima de consumo de sacarose, à qual foi atribuído o valor de 100 .

Os experimentos foram realizados de tal maneira que as fontes de carbono admitidas ao sistema na fase de acúmulo foram consumidas, resultando sempre no meio de fermentação concentrações de substrato iguais a zero.

Assim, as velocidades de consumo destes substratos foram iguais aos fluxos de alimentação destes substratos, valendo para todos os experimentos realizados a igualdade

$\frac{F \times\left(N_{a l .}\right)}{X r \times V}=\frac{1}{X r} \times \frac{d N}{d t}$

Salienta-se que a concentração de células residuais (Xr) foi estabelecida a priori pela composição do meio de cultura da fase de crescimento e que a variação do volume reacional durante a fase de acúmulo era desprezível. Desta maneira, dentro dos limites operacionais dos experimentos, foi possível ajustar a velocidade de consumo dos substratos pela manipulação dos fluxos de entrada destes substratos.

\section{RESULTADOS E DISCUSSÃO}

Constantemente são estudadas diferentes estratégias para obtenção de poli-hidroxialcanoatos, dentre elas o emprego de cepas geneticamente modificadas e diferentes regimes de operação $0^{3,7,14}$. No presente trabalho, foi possível estudar a influência do fluxo de substratos na síntese de biopolímeros com diferentes composições monoméricas (3HB, 3HV e 3HPE) utilizando as linhagens bacterianas B. sacchari IPT 189 e B. cepacia IPT 064.

Para B. sacchari IPT 189, as velocidades de consumo de ácido propiônico e de síntese de unidades de 3HV foram diretamente proporcionais, conforme apresentadas na Figura 2. A manutenção da proporcionalidade em um grande intervalo de variação de velocidades demonstra a rigidez do "nó" reacional entre a oxidação de propionil-CoA e a reação subseqüente de condensação de acetilCoA e propionil-CoA formando valeril-CoA, intermediário da síntese de unidades de $3 \mathrm{HV}$ em $B$. sacchari, com evidente predomínio para a reação de condensação.

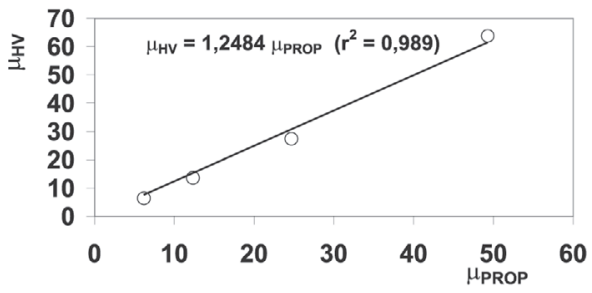

Figura 2. Relação entre velocidades normalizadas de consumo de ácido propiônico $\left(\mu_{\text {prop }}\right)$ e de formação de unidades de $3 H V\left(\mu_{H V}\right)$ na fase de acúmulo do biopolímero P3HB-co-3HV por Burkholderia sacchari IPT 189

O coeficiente angular da reta da Figura 2 expressa o valor do fator de conversão de ácido propiônico a $3 \mathrm{HV}\left(\mathrm{Y}_{3 \mathrm{HV} / \text { prop }}\right)$ e foi de cerca de $1,25 \mathrm{~g} / \mathrm{g}$, muito próximo ao valor máximo teórico $(1,35 \mathrm{~g} / \mathrm{g})^{19}$. Baixas conversões de ácido propiônico em 3HV são apontadas como um dos fatores limitantes na produção de $\mathrm{P} 3 \mathrm{HB}-\mathrm{co}-3 \mathrm{HV}$, elevando o custo do produto final ${ }^{14,23,24}$. Neste sentido, o presente resultado pode ser importante para minimização dos custos de produção deste polímero, uma vez que foi possível modular a composição do copolímero P3HB-co$3 \mathrm{HV}$ oferecendo diferentes relações entre os substratos, sacarose/ácido propiônico, durante a fase de acúmulo. A Tabela 1 apresenta diferentes composições poliméricas em função da relação de consumo dos substratos para B. sacchari IPT 189. O monômero HV variou entre 6,5 até $40 \%$ mol, influenciado diretamente pela concentração de ácido propiônico, ou seja, quanto maior a concentração de ácido propiônico, maior a concentração de unidades de hidroxivalerato formado. 
Tabela 1. Composição do copolímero P3HB-co-3HV em função da razão das velocidades normalizadas de consumo de sacarose e ácido propiônico em B. sacchari IPT 189

\begin{tabular}{lcc}
\hline$\mu_{\mathrm{s}} / \mu_{\text {prop }}$ & $3 \mathrm{HB} \% \mathrm{~mol}$ & $3 \mathrm{HV} \% \mathrm{~mol}$ \\
\hline 2 & 60,0 & 40,0 \\
3,7 & 82,2 & 17,2 \\
7,9 & 89,3 & 10,7 \\
16,2 & 93,5 & 6,5 \\
\hline
\end{tabular}

Por outro lado, a biossíntese de 3HPE em B. cepacia utilizando a linhagem IPT 064, foi inversamente proporcional ao consumo de sacarose (Figura 3). Neste caso, propôs-se a existência de uma via metabólica, ainda não comprovada, para a síntese de unidades de 3HPE a partir da condensação de 2 moles de acetil-CoA gerados da oxidação de sacarose e uma unidade de formil-CoA ou de oxalil-CoA provenientes do ciclo do glioxilato ${ }^{20}$. Este ciclo opera em condições limitadas de aporte de sacarose, provocando a ativação da isocitrato liase, enzima chave do referido ciclo, gerando glioxilato, intermediário que é oxidado até formil-CoA. A Figura 3 mostra o efeito do aporte de sacarose na fase de acúmulo, caracterizado pelo aumento da velocidade normalizada de síntese de 3HPE com limitação do consumo de sacarose $\mu_{\mathrm{s}}$ até cerca de $20 \%$ do valor máximo.

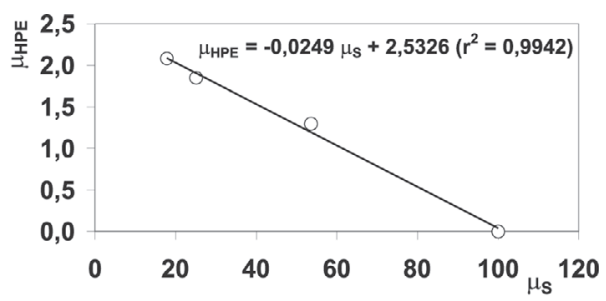

Figura 3. Relação entre velocidades normalizadas de consumo de sacarose $\left(\mu_{S}\right)$ e de formação de unidades de $3 H P E\left(\mu_{H P E}\right)$ na fase de acúmulo do biopolímero P3HB-b-3HPE por Burkholderia cepacia IPT 064

Observa-se na Tabela 2 a composição polimérica da blenda P3HB- $b$-3HPE em função do consumo de substrato para $B$. cepacia IPT 064. Verificou-se que é possível a síntese de vários tipos de blendas de $\mathrm{P}(3 \mathrm{HB}-b-3 \mathrm{HPE})$ com composição variando entre 0 até 8 $\%$ mol de 3HPE pela manipulação do fluxo de entrada de substrato, através de diferentes velocidades de oferta de sacarose. Devido à insaturação neste biopolímero, o grupo vinil do 3HPE é um alvo promissor para a realização de diferentes modificações químicas do polímero. Estas modificações conferem novas propriedades físico-químicas ao P3HB- $b-3 \mathrm{HPE}^{8,15}$. Este resultado pode ser importante para obtenção de matriz de liberação controlada, com diferentes perfis de liberação de fármacos ${ }^{8}$.

Tabela 2. Composição da blenda P3HB- $b$-3HPE em função da razão das velocidades normalizadas de consumo de sacarose em $B$. cepacia IPT 064

\begin{tabular}{lcc}
\hline$\mu_{\mathrm{s}}$ & $3 \mathrm{HB} \% \mathrm{~mol}$ & $3 \mathrm{HPE} \% \mathrm{~mol}$ \\
\hline 100 & 100,0 & 0,0 \\
53,6 & 98,88 & 1,12 \\
25,1 & 95,8 & 4,2 \\
17,9 & 92,08 & 7,92 \\
\hline
\end{tabular}

O presente artigo contribuiu com o estudo de produção de polihidroxialcanoatos bacterianos e estabelece um protocolo para controle da composição destes biopolímeros, através da manipulação do fluxo de substratos.

\section{AGRADECIMENTOS}

À FINEP e ao CNPq que financiaram este projeto e à FAPESP pelas bolsas de Mestrado. Aos técnicos do laboratório de fermentações industriais, V. de Oliveira e R. N. Carvalho.

\section{NOMENCLATURA}

$\mu_{\mathrm{s}} \quad$ Velocidade específica de consumo de sacarose $\quad \mathrm{h}^{-1}$

$\mu_{\mathrm{HPE}} \quad$ Velocidade específica de formação de 3HPE $\mathrm{h}^{-1}$

$\mu_{\mathrm{HV}} \quad$ Velocidade específica de formação de $3 \mathrm{HV} \quad \mathrm{h}^{-1}$

$\mu_{\text {prop }} \quad$ Velocidade específica de consumo de ácido propiônico $\quad h^{-1}$

$\mathrm{Y}_{3 \mathrm{HV} / \mathrm{prop}}$ Fator de conversão de ácido propiônico a unidades de $3 \mathrm{HV} \quad \mathrm{g} / \mathrm{g}$

\section{REFERÊNCIAS}

1. Sudesh, K.; Abe.; H. E.; Doi, Y.; Prog. Polym. Sci. 2000, 25, 1503.

2. Anderson, A. J.; Dawes, E. A.; Microbiol. Rev. 1990, 54, 450.

3. Khanna, S.; Srivastava, A. K.; Process Biochem. 2005, 40, 607.

4. Rodrigues, M. F. A.; Silva, L. F.; Gomez, J. G. C.; Velentim, H. E.; Steinbüchel, A.; Appl. Microbiol. Biotecnhol. 1995, 43, 880.

5. Tavares, L. Z.; Silva, E. S.; Pradella, J. G. C.; Biochemi. Eng. J. 2004, 18, 21.

6. Rocha, R. C. S.; Dissertação de Mestrado, Universidade de São Paulo, Brasil, 2002.

7. Du, G. C.; Chen, J.; Yu, J.; Lun, S.; Biochemi. Eng. J. 2000, 8, 103.

8. Ré, M. I.; Rodrigues, M. F. A.; Silva, E. S.; Castro, I. M.; Simioni, A. R.; Pelisson, M. M. M.; Beltrame J. R. M.; Tedesco, A. C.; Minerva Biotecnologica 2006, 18, 3 .

9. Hrabak, O.; FEMS Microbiol. Rev. 1992, 103, 251.

10. Doi, Y.; Microbial Polyesters. VHC Publishers: New York, 1990.

11. Byrom, D. Em Novel biodegradable microbial polymers; Dawes, E. A., ed.; Kluwer: London, 1990

12. Jackson, D. E.; Srienc, F.; Ann. New York Acad. Sci., 1995, 175, 134.

13. Steinbüchel, A.; Valentim, H. E.; FEMS Microbiol Lett. 1995, 125, 219.

14. Silva, L. F.; Gomez, J. G. C.; Oliveira, M. S.; Torres, B. B.; J. Biotechnol. 2000, 76, 165 .

15. Valentim, H. E.; Berger, P. A.; Gruys, K. J.; Rodrigues, M. F. A.; Steinbuchel, A.; Tran, M.; Asrar, J.; Macromolecules 1999, 32, 7389.

16. Brämer, C. O.; Silva, L. F.; Gomez, J. G. C.; Steinbüchel, A.; Appl. Environ. Microbiol. 2002, 68, 271.

17. Ramsay, B. A.; Lomaliza, K.; Chavarie, C.; Dubé, B.; Bataile, P.; Ramsay, J.; Appl. Environ. Microbiol. 1990, 61, 2487.

18. Pfennig, N.; Arch. Microbiol. 1974, 2, 100.

19. Gomez, J. G. C.; Rodrigues, M. F. A.; Alli, R. C. P.; Torres, B. B.; Bueno Netto, C. L.; Oliveira, M. S.; Silva, L. F.; Appl. Microbiol. Biotechnol. 1996, 45,785 .

20. Pereira, F.S.; Dissertação de Mestrado, Universidade de São Paulo, Brasil, 2003.

21. Riss, V.; Mai, W.; J. Chromatogr., A 1988, 445, 285.

22. Diniz, S. C.; Taciro, M. K.; Gomez, J. G. C.; Pradella, J. G. C.; Appl. Biochem. Biotechnol. 2004, 119, 51.

23. Choi, J.; Lee, S. Y.; Appl. Microbiol. Biotechnol. 1999, 51, 13.

24. Squio, C. R.; Aragão, G. M. F.; Quim. Nova, 2004, 27, 615. 